\title{
Antiapoptotic effect of haem oxygenase-I induced by nitric oxide in experimental solid tumour
}

\author{
S Tanaka',2, T Akaike', J Fang', T Beppu', M Ogawa' ${ }^{2}$ F Tamura', Y Miyamoto' and H Maeda*,' \\ 'Department of Microbiology, Kumamoto University School of Medicine, 2-2-I Honjo, Kumamoto 860-08 I I, Japan; ${ }^{2}$ Department of Surgery, Kumamoto \\ University School of Medicine, 2-2-1 Honjo, Kumamoto 860-0811, Japan
}

\begin{abstract}
Induction of haem oxygenase-I (HO-I) may provide an important protective effect for cells against oxidative stress. Here, we investigated the mechanism of cytoprotection of $\mathrm{HO}-\mathrm{I}$ in solid tumour with a focus on the antiapoptotic activity of $\mathrm{HO}-\mathrm{I}$. Treatment of rat hepatoma $\mathrm{AHI} 36 \mathrm{~B}$ cells with the $\mathrm{HO}$ inhibitor zinc protoporphyrin IX (ZnPP IX) or tin protoporphyrin IX resulted in extensive apoptotic changes of tumour cells both in vivo and in vitro. Caspase-3 activity of the ZnPP IX-treated hepatoma cells increased significantly. Moreover, ZnPP IX-induced apoptosis was completely inhibited by simultaneous incubation with a specific caspase-3 inhibitor and was partially abrogated by bilirubin, a reaction product of $\mathrm{HO}$. In vivo ZnPP IX treatment did not affect nitric oxide ( $\mathrm{NO}$ ) production and tumour blood flow. Western blot analyses showed that $\mathrm{HO}-\mathrm{I}$ expression in $\mathrm{AHI} 36 \mathrm{~B}$ cells was strongly upregulated by $\mathrm{NO}$ donors, for example, S-nitroso-N-acetyl penicillamine and propylamine NONOate in vitro; conversely, it was remarkably reduced in vivo by pharmacological blockade of NOS. We conclude that $\mathrm{HO}-\mathrm{I}$ may function in antiapoptotic defense of the tumour, and thus it may have important protective and beneficial effects for tumour cells against oxidative stress induced by $\mathrm{NO}$, which is produced in excess during solid tumour growth in vivo.

British Journal of Cancer (2003) 88, 902-909. doi: I 0.1038/sj.bjc.6600830 www.bjcancer.com
\end{abstract}

(c) 2003 Cancer Research UK

Keywords: nitric oxide; haem oxygenase; antiapoptosis; oxidative stress; tumour growth

Haem oxygenase (HO) is the rate-limiting enzyme in haem degradation; this reaction produces biliverdin, which is subsequently converted to bilirubin by biliverdin reductase in biological systems (Tenhunen et al, 1968). Haem oxygenase -2 (HO-2) is the constitutive isoform of $\mathrm{HO}$ and is highly expressed in testis and brain under physiological conditions (Manies, 1997). Haem oxygenase -1 (HO-1), the inducible isoform of $\mathrm{HO}$, also known as heat shock protein 32 (HSP32), is found at low levels in most mammalian tissues, but it is constitutively expressed in liver and spleen and is upregulated by its substrate haem (Tenhunen et al, 1970) and various stress-inducing stimuli such as UV light (Keyse and Tyrrell, 1989), heavy metals (Mitani et al, 1993), heat shock (Shibahara et al, 1987), hypoxia (Motterlini et al, 2000), and nitric oxide (NO) (Kim et al, 1995; Foresti and Motterlini, 1999; Bouton and Demple, 2000). Induction of HO-1 is suggested to have a cytoprotective effect against oxidative injury (Dennery et al, 1997; Suttner et al, 1999), because some bile pigments formed via HO have been shown to behave as antioxidants (Minetti et al, 1998; Dore et al, 1999).

We previously showed in an experimental solid tumour that NO produced in excess in the local area surrounding tumour cells seemed to sustain rapid tumour growth (Doi et al, 1996). It has been reported, however, that a particularly high output of NO from inducible nitric oxide synthase (iNOS) is potentially cytotoxic for

*Correspondence: Dr H Maeda;

E-mail: msmaedah@gpo.kumamoto-u.ac.jp

Received 7 May 2002; revised 28 November 2002; accepted 20 December 2002 various tumour cells (Bastian et al, 1994). In this context, our earlier study indicated that HO-1 is upregulated by NO produced by iNOS in an experimental solid tumour (Doi et al, 1999). Haem oxygenase-1 may provide important protection for tumour cells, so that tumour cell growth is sustained by HO-1 even under oxidative stress induced by excessive NO. In fact, we found that tumour growth was remarkably suppressed by the administration of zinc protoporphyrin IX (ZnPP IX, an HO-1 inhibitor) to tumourbearing rats (Doi et al, 1999). However, these cytoprotective mechanisms of HO-1 remain to be identified.

It is intriguing that overexpression of $\mathrm{HO}-1$ protects endothelial cells from apoptosis induced by the host's rejection reaction in a rodent cardiac transplantation model (Hancock et al, 1998; Soares et al, 1998). In the present study, we investigated the mechanism of HO-1 cytoprotection of tumour cells, with a focus on the antiapoptotic potential of HO-1, which may contribute in a critical way to tumour growth in vivo.

\section{MATERIALS AND METHODS}

\section{Animals and implantation of AH136B tumour}

AH136B tumour (rat hepatoma) cells were implanted subcutaneously (s.c.) in a dorsal site on the foot of male Donryu rats weighing 160-180 g (SLC, Inc., Shizuoka, Japan) with an inoculum size of $1 \times 10^{7}$ cells per injection site as described previously (Doi et al, 1996). Tumours were allowed to grow for 14 days and usually reached a diameter of $10-15 \mathrm{~mm}$. We used the tumours with about $10 \mathrm{~mm}$ in diameter for the present studies. The solid tumour did 
not cause apparent physical effects for the tumour-bearing animals: no motor dysfunctions of the limb including paralytic and shuffling gaits and no apparent symptoms of peripheral circulatory failure in the distal area of the tumour implantation site (nor necrosis) were observed during this experiment. All animal experiments were carried out with approval by the Ethical Committee at the Center for Animal Resources and Development, Kumamoto University, which met the standard required by the United Kingdom Co-ordinating Committee on Cancer Research (UKCCCR) guidelines (Workman et al, 1998).

\section{Treatment of AH136B solid tumour with $\mathrm{ZnPP}$ IX in vivo}

For the treatment of AH136B tumour in vivo, $500 \mu \mathrm{g} \mathrm{kg}^{-1} \mathrm{ZnPP}$ IX (Sigma-Aldrich Fine Chemicals, St Louis, MO, USA) or copper protoporphyrin IX (CuPP IX, Frontier Scientific Inc., Logan, UT, USA) (500 $\mu \mathrm{g}$ of each in $1 \mathrm{ml}$ of $10 \%$ dimethyl sulphoxide (DMSO) in $0.01 \mathrm{M} \mathrm{NaOH}$ ) was injected intra-arterially (i.a.) into solid tumour via the common iliac artery that is mainly feeding the tumour, so that effective delivery of these compounds is achieved. Solid tumours were obtained $24 \mathrm{~h}$ after injection and were stored at $-80^{\circ} \mathrm{C}$ until use for terminal deoxynucleotidyl transferase (TdT)mediated dUTP-biotin nick end-labelling (TUNEL) staining and for analyses of HO-1 and HSP70.

\section{Analysis for apoptosis and viability of AH136B cells treated with HO inhibitors in vitro}

AH136B tumour cells, at $5 \times 10^{5}$ cells per well of a six-well polystyrene plate (Falcon, Becton Dickinson Labware, Lincoln Park, NJ, USA), were incubated with various concentrations of the HO inhibitors ZnPP IX and tin protoporphyrin IX (SnPP IX, Frontier Scientific) (Drummond and Kappas, 1981) in Dulbecco's minimum essential medium (Invitrogen Corp., Carlsbad, CA, USA) supplemented with $10 \%\left(\mathrm{vv}^{-1}\right)$ fetal bovine serum and $0.5 \%$ nonessential amino acids (Invitrogen). After $24 \mathrm{~h}$ of culture, the cells were subjected to the cell viability and apoptosis assays of TUNEL staining and caspase- 3 activity determination. Similarly, the cells were treated with CuPP IX, which has no direct inhibitory effect on HO activity in vivo (Drummond and Kappas, 1981) and is a poor HO inhibitor in vitro (Zakhary et al, 1996). Also, the effects of ZnPP IX on cultured cells were examined in the presence of bilirubin (Wako Pure Chemical Co., Ltd, Osaka, Japan) or caspase3 inhibitor (acetyl-Asp-Met-Gln-Asp-CHO; Peptide Institute, Inc., Osaka, Japan). Cell viability was determined via the trypan blue dye exclusion assay (Kimura et al, 1990). Analyses for TUNEL staining and caspase-3 activity were performed as described below.

\section{Effect of NO on expression of HO-1 and HSP in AH136B tumours}

Tumour-bearing rats were administered either $N^{\omega}$-nitro-L-arginine methyl ester (L-NAME, Sigma-Aldrich Fine Chemicals) or $S$ methylisothiourea sulphate (SMT, Wako Pure Chemical Co., Ltd) in $0.2 \mathrm{ml}$ of $0.9 \% \mathrm{NaCl}$ solution, given intraperitoneally (i.p.) at a dose of $6 \mathrm{mg} \mathrm{kg}^{-1}$ per day for 5 days, beginning 9 days after tumour implantation. Solid tumour tissues were obtained 1 day after the last injection of NOS inhibitor and were stored at $-80^{\circ} \mathrm{C}$ until use for HO-1 and HSP70 Western blotting. The effect of ischaemic stress on the expression of HSP70 protein in solid tumour was also examined. Briefly, on day 14 after tumour implantation, solid tumours were resected for Western blot analysis at different times after initiation of surgical occlusion of the common iliac artery, which serves the tumour-feeding artery of the tumour-implanted side. In addition, the effect of NO on the expression of HO-1 and HSP70 was examined with the use of AH136B cells in culture treated with the NO donors $S$-nitroso- $N$ acetyl penicillamine (SNAP, Dojindo Laboratories, Kumamoto,
Japan) and propylamine NONOate $\left(\mathrm{CH}_{3} \mathrm{~N}[\mathrm{~N}(\mathrm{O})\right.$ $\mathrm{NO}]^{-}\left(\mathrm{CH}_{2}\right)_{3} \mathrm{NH}_{2}^{+} \mathrm{CH}_{3}$ ) (P-NONOate, Dojindo Laboratories). Western blotting was used to analyse the levels of HO-1 and HSP70 proteins in lysate of the AH136B cells, after a 6-h incubation with the NO donors.

\section{TUNEL assay}

Suspensions of cultured AH136B cells, treated with various compounds as just described, were spotted onto glass microscope slides and were dried at room temperature, followed by TUNEL staining. For the analysis of solid tumour tissues, $6-\mu \mathrm{m}$-thick frozen tissue sections were prepared with a cryostat and were airdried overnight. Apoptotic cells were detected via the TUNEL method by using an apoptosis detection kit (TACS; Trevigen Inc., Gaithersburg, MD, USA) (Ikebe et al, 2000).

\section{Caspase-3 assay of AH136B tumour cells}

Caspase-3 activity in AH136B tumour cells was measured as described previously (Enari et al, 1996). Briefly, lysates of AH136B cells, having had treatment with various compounds or no treatment, were incubated for $30 \mathrm{~min}$ at $37^{\circ} \mathrm{C}$ with $1 \mu \mathrm{M} \mathrm{MOCAc-}$ Asp-Glu-Val-Asp-Ala-Pro-Lys(Dnp)- $\mathrm{NH}_{2}$ fluorescent substrate (Peptide Institute). Ac-DMQD-CHO, caspase-3 inhibitor (Peptide Institute), was added to the reaction mixture at a concentration of $10 \mu \mathrm{M}$. Caspase-like amidolytic activity for the peptidyl substrate was measured fluorometrically and caspase activity was determined by subtracting the fluorescence values obtained in the presence of inhibitor.

\section{Measurement of $\mathrm{HO}$ activity in tumour cells and solid tumours}

Haem oxygenase activity in AH136B tumour cells and solid tumours was quantified with use of the microsomal fraction extracted from each sample according to our previously described method (Doi et al, 1999). The reaction mixture for the measurement of $\mathrm{HO}$ activity was composed of microsomal protein $(1 \mathrm{mg})$, cytosolic fraction of rat liver (1 $\mathrm{mg}$ protein) as a source of biliverdin reductase, $33 \mu \mathrm{m}$ hemin, and $333 \mu \mathrm{M}$ NADPH of $1 \mathrm{ml}$ of $90 \mathrm{~mm}$ potassium phosphate buffer, $\mathrm{pH}$ 7.4. The bilirubin formed in the reaction $\left(15 \mathrm{~min}\right.$ at $\left.37^{\circ} \mathrm{C}\right)$ was quantified spectroscopically (Doi et al, 1999).

\section{In vivo microdialysis}

This technique was employed to assess the NO production in tumour tissue in vivo (Ohta et al, 1994). A microdialysis probe (straight type, outer diameter $220 \mu \mathrm{m}$, length $5 \mathrm{~mm}$, cellulose membrane, cutoff $50000 \mathrm{Da}$; Eicom Corp., Kyoto, Japan) was implanted in the solid tumour, and was perfused using a microsyringe pump (ESP-64, Eicom Corp.). After an equilibration period $(1 \mathrm{~h})$, dialysate was collected in polyethylene tubes for $15 \mathrm{~min}$, followed by measurement of $\mathrm{NO}_{2}^{-}$and $\mathrm{NO}_{3}^{-}$by using an $\mathrm{NO}_{x}$ analyzer (ENO-10, Eicom Corp.) (Akaike et al, 1997).

\section{Measurement of tumour blood flow}

Tumour blood flow was measured before and 1, 3, 6, 12, and $24 \mathrm{~h}$ after injection of $500 \mu \mathrm{g} \mathrm{kg}^{-1} \mathrm{ZnPP}$ IX via the tumour-feeding artery or after i.p. injection of $6 \mathrm{mg} \mathrm{kg}^{-1}$ L-NAME. A laser Doppler flowmeter (Laser Flow Meter, ALF21, Advance, Tokyo, Japan) was used for measurement of the tumour blood flow via a probe needle placed into the tumour tissue as described earlier (Ikebe et al, 2000). 


\section{Western blotting for expression of HO-1 and HSP70}

Lysates of AH136B cells treated or untreated with various reagents were prepared as described previously (Doi et al, 1999). HSP70 was induced by a standard heat shock treatment at $42^{\circ} \mathrm{C}$ for $30 \mathrm{~min}$ followed by a 6-h incubation under normal culture conditions as described above. The supernatant of homogenates $(10000 \mathrm{~g}$, $30 \mathrm{~min})$ of tumour tissues treated with ZnPP IX $\left(500 \mu \mathrm{g} \mathrm{kg}^{-1}\right.$, i.a.), NOS inhibitors, or vehicle was subjected to Western blot analysis for HSP70. The microsomal fraction obtained by ultracentrifugation was used for the HO-1 analysis. Total protein ( $25 \mu \mathrm{g}$ each) in cell lysates or tissue homogenates was used for the Western blotting with a monoclonal antibody to HSP70 (SPA-810, Stressgen, Victoria, BC, Canada), which specifically recognises the inducible but not the constitutive isoforms of the HSP70 family in mammals, or a polyclonal antibody to HO-1 (OSA-150, Stressgen). The protein band that reacted immunologically with the antibody was visualised by using the ECL system (Amersham International plc, Buck, UK).

\section{Statistical analysis}

Data are shown as means \pm s.e. Statistical difference was analysed by the use of the two-tailed unpaired $t$-test and by ANOVA. A $P$ value of $<0.05$ was considered statistically significant.

\section{RESULTS}

Zinc protoporphyrin IX -induced apoptosis and inhibition of $\mathrm{HO}$ activity in AH136B solid tumours

Strong staining of TUNEL-positive cells was detected in ZnPP IXtreated tumour tissue (Figure 1A, B); however, the vehicle (control) (Figure 1A, A) and the CuPP IX-treated (Figure 1A, C) tumour tissues showed only negligible staining. Morphometric analysis of
TUNEL-positive cells in AH136B solid tumours revealed a significantly higher number of TUNEL-positive cells in the ZnPP IX-treated group $\left(210 \pm 6 \mathrm{~mm}^{-2}\right)$ compared with the control group $\left(14 \pm 2 \mathrm{~mm}^{-2}\right)$ and the CuPP IX-treated group $\left(20 \pm 4 \mathrm{~mm}^{-2}\right)$ (Figure 1B).

A significant, although not complete, inhibition of $\mathrm{HO}$ activity in solid tumour tissue was obtained by ZnPP IX treatment (Figure 1C). The CuPP IX-treated group showed almost the same level of $\mathrm{HO}$ activity as the control group. These results suggest that $\mathrm{ZnPP}$ IX-induced apoptosis in AH136B solid tumour is mediated through the inhibition of HO activity by ZnPP IX.

\section{Zinc protoporphyrin IX-induced apoptosis and inhibition of $\mathrm{HO}$ activity in AH136B cells in culture}

Cultured AH136B cells were incubated for $24 \mathrm{~h}$ with indicated concentrations of ZnPP IX (with or without a caspase-3 inhibitor) or SnPP IX, or with $100 \mu \mathrm{M}$ CuPP IX (Figure 2). The number of TUNEL-positive cells in the CuPP IX-treated group $(8.1 \pm 1.3 \%)$ was comparable to that of the control group $(6.6 \pm 3.8 \%)$. In contrast, $1 \mu \mathrm{M}$ and higher concentrations of ZnPP IX potentiated the induction of apoptosis in AH136B cells in a concentrationdependent manner (46.7\% at $100 \mu \mathrm{M} \mathrm{ZnPP)} \mathrm{(Figure} \mathrm{2A).} \mathrm{A} \mathrm{similar}$ trend for the induction of apoptosis was observed with another $\mathrm{HO}$ inhibitor, SnPP IX (Figure 2B). The ZnPP IX-induced apoptosis was completely inhibited by simultaneous incubation with a specific caspase-3 inhibitor (at 1 or $10 \mu \mathrm{M}$ ). The viability of tumour cells was inversely decreased in a concentration-dependent manner after ZnPP IX treatment (inset in Figure 2A, B). Figure 2C shows representative TUNEL staining of control and ZnPP IX-treated tumour cells $(100 \mu \mathrm{M}$ ZnPP IX), illustrating a considerable number of TUNEL-positive cells in the ZnPP IXtreated group compared with the control staining.

Zinc protoporphyrin IX treatment resulted in a remarkable reduction of $\mathrm{HO}$ activity in the cells (Figure $3 \mathrm{~A}$ ), which correlated
A
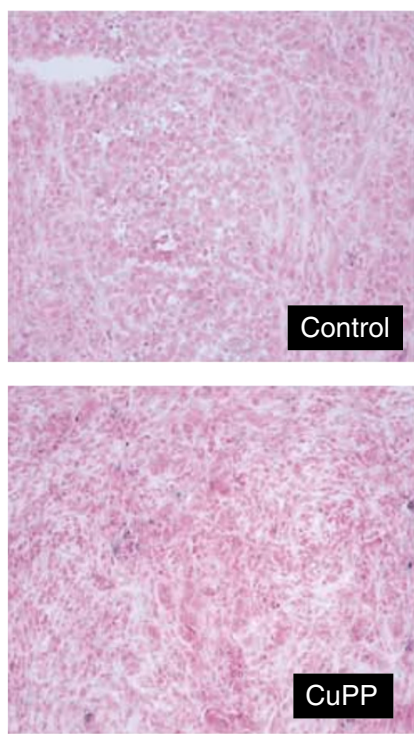
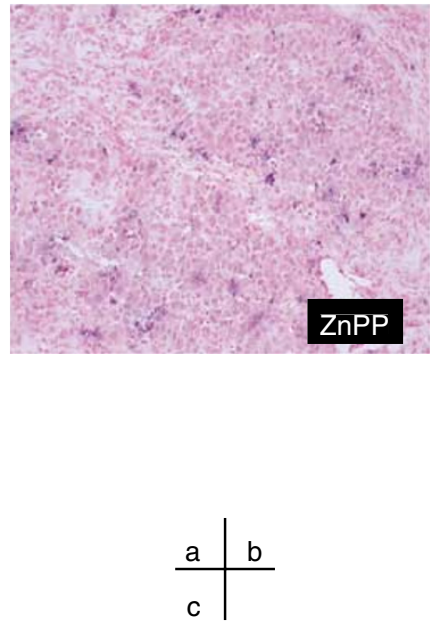

$100 \mu \mathrm{M}$
B

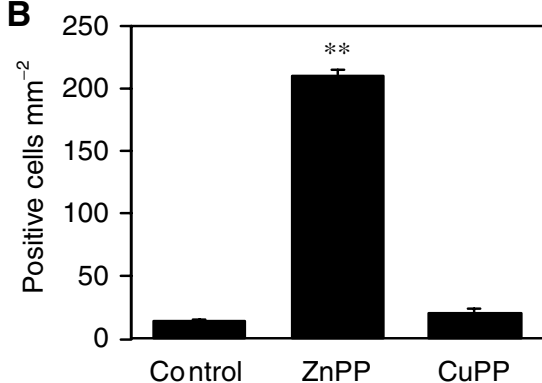

C

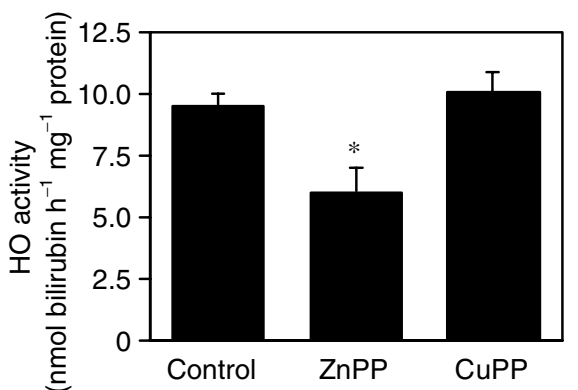

Figure I Apoptosis induction and change in $\mathrm{HO}$ activity after treatment with $\mathrm{ZnPP}$ IX of $\mathrm{AHI} 36 \mathrm{~B}$ solid. Apoptosis (A, B) and HO activity (C) were assessed on day 14 after tumour implantation. Each specimen was analysed via TUNEL staining $24 \mathrm{~h}$ after treatment with vehicle (the control) (A, a), with ZnPP IX (500 $\mathrm{g} \mathrm{kg}^{-1}$ i.a.) (A, b), or with CuPP IX (500 $\mathrm{g} \mathrm{kg}^{-1}$ i.a.) (A, c). Quantitative analysis of TUNEL-positive cells in each specimen is shown (B). TUNEL-positive cells were counted in four different fields of magnification at $\times 100$ per sample, and then the number of positive cells per mm ${ }^{2}$ was calculated. Haem oxygenase activity of the solid tumour was measured after treatment in the same manner as in the TUNEL analysis $(\mathbf{C})$. $* P<0.05$, $* * P<0.0$ l vs control ( $n=3$ for each group). Data are means \pm s.e. See text for details. 
A


2 Zinc protoporphyrin IX-induced apoptosis of AHI36B cells in vitro. AHI36B cells were incubated for $24 \mathrm{~h}$ with indicated concentrations of ZnPP IX, with or without caspase-3 inhibitor (A) or SnPP IX (B), or with $100 \mu$ M CuPP IX. (A, B) TUNEL-positive cells were counted in four different fields of magnification at $\times 100$ per sample, and then the percentage of positive cells was calculated. $* P<0.05$ vs control ( $n=3$ for each group). Cell viability after the same treatment is shown in the inset. $* P<0.05, * * P<0.0$ I vs control ( $n=4$ for each group). Data are means \pm s.e. (C) Representative TUNEL staining of control and ZnPP IX-treated tumour cells. See text for details.

very well with the level of apoptosis caused by ZnPP IX treatment (Figure 2). Copper protoporphyrin IX, which showed no appreciable apoptotic effect, also did not affect cellular HO activity (Figure 3A). In addition, caspase- 3 activity in AH136B cells was greatly increased after $24 \mathrm{~h}$ of incubation with $100 \mu \mathrm{M} \mathrm{ZnPP}$ IX, and this increase was totally nullified by simultaneous incubation with caspase- 3 inhibitor at concentrations of 1 and $10 \mu \mathrm{m}$ (Figure 3B). These results are consistent with the finding from the in vivo solid tumour study and indicate again that pharmacological blockade of $\mathrm{HO}$ activity induces apoptotic change of the AH136B tumour cells.

\section{Protective effect of bilirubin against ZnPP IX-induced apoptosis of AH136B cells}

We further examined the effect of bilirubin, which is biologically derived from biliverdin, an important enzymatic reaction product of $\mathrm{HO}$ (Figure 4). There was a trend toward inhibition of ZnPP IXinduced apoptosis even at $0.001 \mu \mathrm{M}$ bilirubin, although it was not statistically significant. Addition of $0.01 \mu \mathrm{M}$ or higher concentrations of bilirubin caused a marked reduction in the number of TUNEL-positive cells. This suppressive effect of bilirubin on ZnPP IX-induced apoptosis of AH136B cells was not truly dose dependent, however, and one-third of the TUNEL-positive cells remained unaffected at the highest concentration of bilirubin $(100 \mu \mathrm{M})$

\section{Effect of ZnPP IX treatment on blood flow and NO production in AH136B solid tumours}

Carbon monoxide ( $\mathrm{CO}$ ) generated by $\mathrm{HO}$ has been demonstrated to be a potential endogenous modulator of vascular tone in the liver (Suematsu et al, 1994). Hence, we examined whether ZnPP IX treatment modulated blood flow in this solid tumour through the inhibition of CO biosynthesis (Figure 5). Tumour blood flow was not affected by ZnPP IX in this model, although it was significantly decreased 1, 3, 6, and $12 \mathrm{~h}$ after administration of L-NAME. Moreover, ZnPP IX did not appreciably affect NO production in AH136B solid tumours, as evidenced by the microdialysis technique to analyse the amount of $\mathrm{NO}_{2}^{-}$and $\mathrm{NO}_{3}^{-}$in situ generated in the dialysate of the tumour tissues: $3.5 \pm 1.1$ and $3.2 \pm 1.4 \mu \mathrm{M}$ of $\mathrm{NO}_{2}^{-}$and $\mathrm{NO}_{3}^{-}$were generated for $15 \mathrm{~min}$ in $10 \mu \mathrm{l}$ dialysates of the tumour tissues before and $24 \mathrm{~h}$ after ZnPP IX treatment, respectively $(n=5$ for each group; $P=0.67)$. No appreciable suppression for NO production was observed at any time points $(1,2,3,6$, and $12 \mathrm{~h})$ after ZnPP IX administration (data not shown).

\section{Expression of HSP70 and HO-1 proteins in AH136B cells and solid tumours}

Western blotting was performed to analyse the expression of HO-1 protein and another important HSP, HSP70, in AH136B tumour cells and solid tumour tissues (Figure 6). Not only AH136B cells in culture but also AH136B solid tumours grown in vivo show constitutive expression of HSP70 and HO-1 proteins without any particular stimulation. The levels of expression of both of these proteins were strongly upregulated by heat shock treatment. The expression of HO-1 was also greatly enhanced by NO generated exogenously from SNAP or P-NONOate added to the culture of the AH136B tumour cells (Figure 6A, upper panel), whereas the same treatment produced no measurable change in HSP70 expression (Figure 6A, lower panel). Also, ZnPP IX treatment of the cultured 

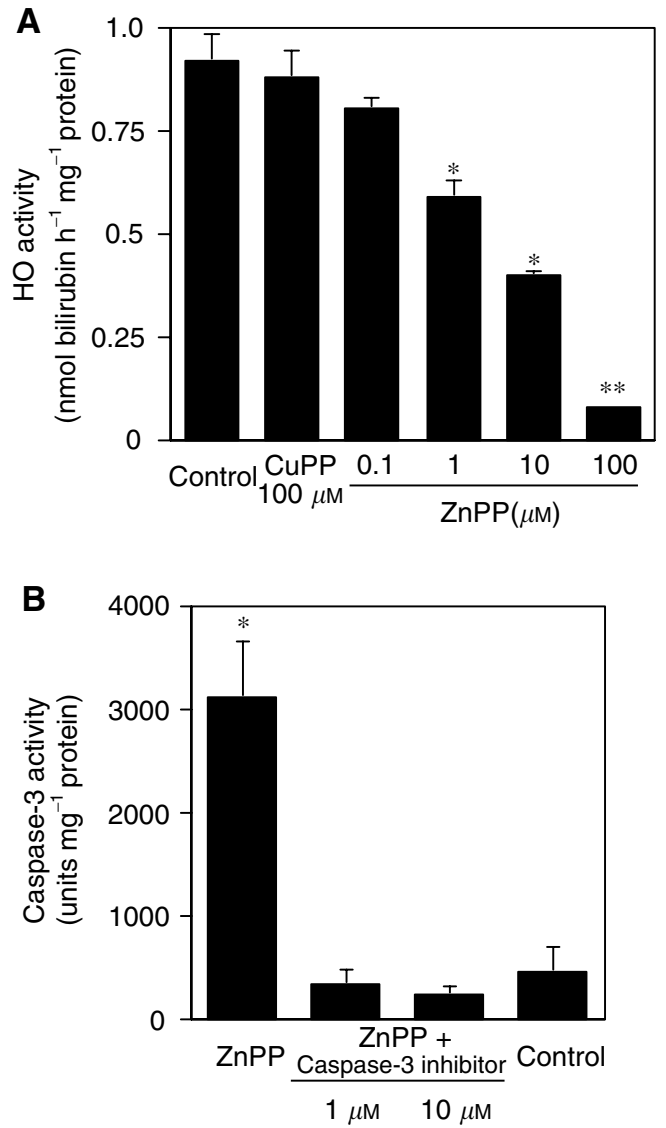

Figure 3 Effect of ZnPP IX on $\mathrm{HO}$ activity and caspase-3 activity of $\mathrm{AHI} 36 \mathrm{~B}$ cells cultured in vitro. Haem oxygenase activity was measured $24 \mathrm{~h}$ after incubation with vehicle (control), ZnPP IX, or CuPP IX (A). Similarly, cells were treated with $100 \mu \mathrm{M} Z \mathrm{nPP}$ with or without caspase-3 inhibitor (I or $10 \mu \mathrm{M}$ ) for $24 \mathrm{~h}(\mathbf{B})$. Caspase-3 activity was measured fluorometrically in cell extracts by using a fluorescent substrate. $* P<0.05, * * P<0.0$ I vs control ( $n=3$ for each group). Data are means \pm s.e. See text for details.



Figure 4 Protective effect of bilirubin against ZnPP IX-induced apoptosis of $\mathrm{AHI} 36 \mathrm{~B}$ cells. AHI36B cells were incubated for $24 \mathrm{~h}$ with $100 \mu \mathrm{M} \mathrm{ZnPP}$ $\mathrm{IX}$ in the presence or absence of indicated concentrations of bilirubin. TUNEL-positive cells were counted in four different fields of magnification at $\times 100$ per sample, and then the percentage of positive cells was calculated. $* P<0.05$ vs ZnPP IX alone ( $n=3$ for each group). Data are means \pm s.e. See text for details.

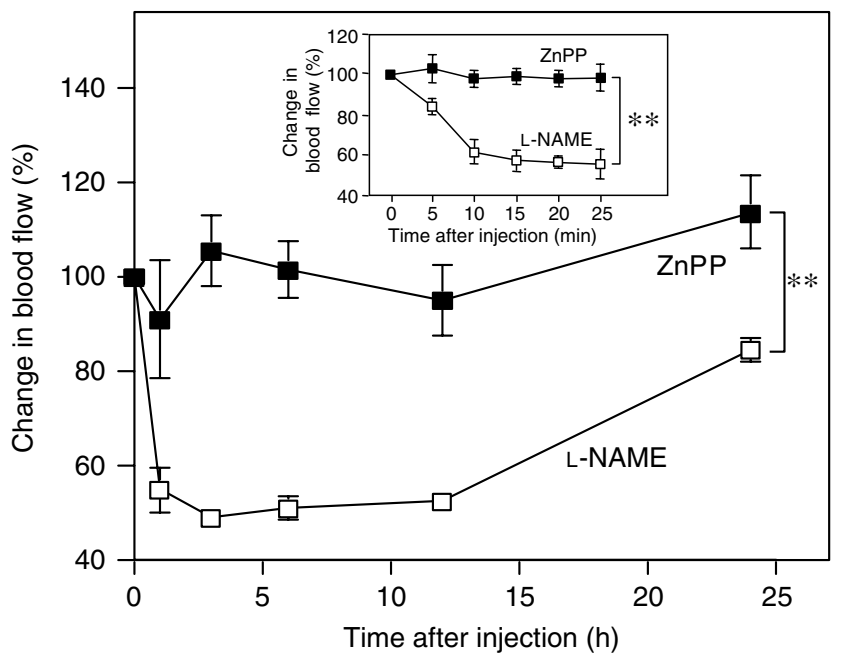

Figure 5 Tumour blood flow after ZnPP IX or L-NAME treatment. Tumour blood flow was measured in AHI36B solid tumour on day 14 after tumour implantation. At the indicated times after injection of $500 \mu \mathrm{g} \mathrm{kg}^{-}$ ZnPP IX (i.a.) or $6 \mathrm{mg} \mathrm{kg}^{-1}$ L-NAME (i.p.), a laser Doppler flowmeter and a probe needle were used to measure blood flow. Relative changes in tumour blood flow after injection of ZnPP IX or L-NAME are shown. Inset, change in tumour blood flow during early period after treatment (within $25 \mathrm{~min}$ ). $* * P<0.0$ I by ANOVA between the groups ( $n=3$ for each time point). Data are means \pm s.e. See text for details.

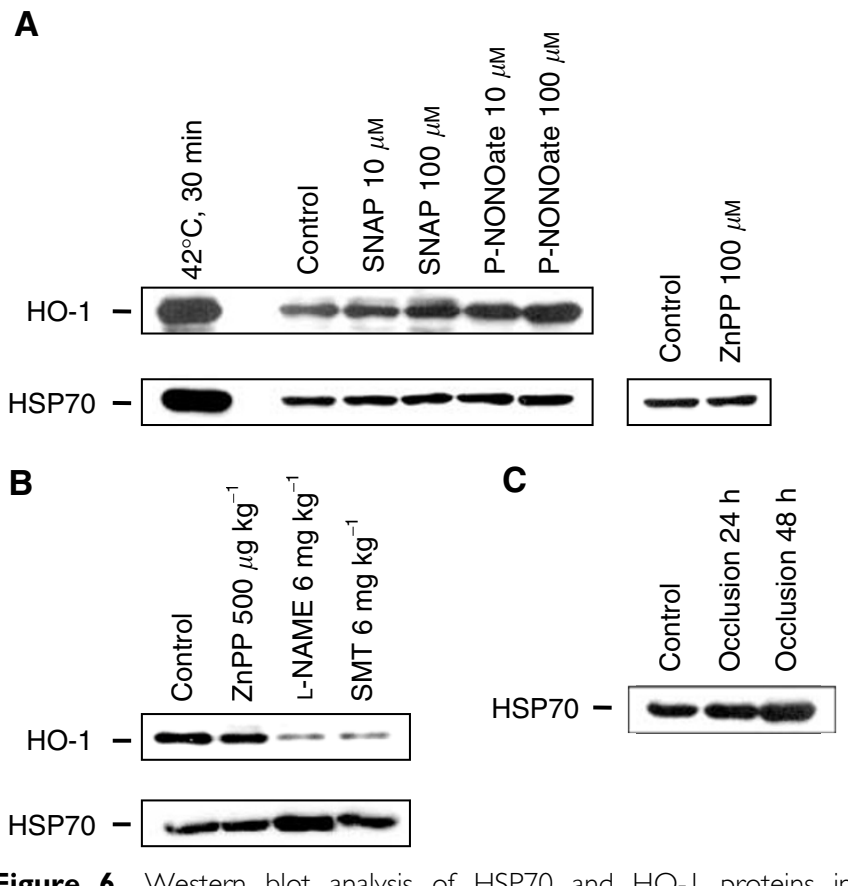

Figure 6 Western blot analysis of HSP70 and $\mathrm{HO}-\mathrm{I}$ proteins in AHI36B cells and solid tumours. (A) Cells were incubated with SNAP (I0 or $100 \mu \mathrm{M})$, P-NONOate $(10$ or $100 \mu \mathrm{M})$, or $\mathrm{ZnPP} I X(100 \mu \mathrm{M})$ for $6 \mathrm{~h}$ or, as a positive control, were treated by heat at $42^{\circ} \mathrm{C}$ for $30 \mathrm{~min}$, followed by incubation at $37^{\circ} \mathrm{C}$ for $6 \mathrm{~h}$. (B) AHI36B solid tumours were treated with $0.9 \% \mathrm{NaCl}$ solution (control), ZnPP IX $\left(500 \mu \mathrm{g} \mathrm{kg}{ }^{-1}\right.$ i.a.), L-NAME $\left(6 \mathrm{mg} \mathrm{kg}^{-1} \mathrm{day}^{-1}\right.$ for 5 days i.p.), or SMT $\left(6 \mathrm{mg} \mathrm{kg}^{-1}\right.$ day $^{-1}$ for 5 days i.p.). (C) Solid tumours were resected at 24 or $48 \mathrm{~h}$ after initiation of surgical occlusion of the common iliac artery, which serves the tumourfeeding artery of the tumour-implanted side. Control rats were treated by sham operation. Then, expression of HSP7O and HO-I proteins was detected by Western blotting by using a monoclonal antibody to mammalian inducible HSP70 or a polyclonal antibody to rat HO-I. Each data point shown represents three independent experiments. See text for details. 
tumour cells had no effect on HSP70 expression (Figure 6A, lower panel). Similarly, ZnPP IX administration to solid tumour tissues did not influence HO-1 or HSP70 expression in vivo (Figure 6B), suggesting no compensatory regulation of HO-1 and HSP70.

Haem oxygenase- 1 expression in $\mathrm{AH} 136 \mathrm{~B}$ tumour tissues in vivo was strongly attenuated by treatment with L-NAME or SMT (Figure 6B, upper panel), which is consistent with the in vitro result of strong upregulation of HO-1 in AH136B tumour cells induced by NO. In contrast, the level of HSP70 expression was increased by the same NOS inhibitor treatment (Figure 6B, lower panel). This upregulation of HSP70 by NOS inhibitors was possibly caused by hypoxic stress of the solid tumour tissues produced by blockade of NO biosynthesis. The same HSP70 upregulation occurred after an ischaemic insult caused by occlusion of the tumour-feeding artery (Figure 6C). These data indicate that HO-1 expression was regulated mainly by NO generated endogenously in the solid tumour tissue, whereas HSP70 expression was modulated through a separate mechanism, possibly dependent on a hypoxic cellular signalling pathway of the tumour cells.

\section{DISCUSSION}

In the present study, we clearly demonstrate that HO-1 induced by NO had a potent antiapoptotic function in an experimental AH136B solid tumour in rats. Earlier studies suggested a cytoprotective effect of HO-1, that is, inhibition of apoptosis in transplant injury during organ rejection and of TNF- $\alpha$-induced apoptosis in fibroblasts (Hancock et al, 1998; Soares et al, 1998; Petrache et al, 2000). Here, we found that ZnPP IX induced the apoptosis of $\mathrm{AH} 136 \mathrm{~B}$ cells both in vivo and in vitro through inhibition of HO-1 activity, and HO-1 activity was upregulated by NO generated in the tumour tissues. It was recently reported that ZnPP IX had a direct cytotoxic effect through apoptosis induction, regardless of HO inhibition (Lutton et al, 1997). Another potent HO inhibitor is, however, shown not to have such a direct cytotoxic (apoptotic) effect (Yang et al, 2001). In our study, not only ZnPP IX but also SnPP IX, which inhibits HO specifically without direct cytotoxic action, showed potent apoptosis-inducing potential in AH136B tumour cells. In addition, ZnPP IX treatment of the rats did not affect the blood flow in the tumour tissue (Figure 5), suggesting that ZnPP IX does not have a significant inhibitory effect at least on the soluble guanylate cyclase activity as seen in blood flow (via NO-cGMP pathway), which is a major inducer for vasorelaxation. It is thus reasonable to conclude that the HO-1 expressed by the tumour cells may have a cytoprotective function, so that the solid tumour can grow effectively during the oxidative stress that occurs as the tumour grows.

To further confirm the antiapoptotic activity of $\mathrm{HO}-1$, we performed a separate experiment by using a small interfering RNA (siRNA) to suppress specifically the expression of HO- 1 . Specifically, endogenous HO-1 mRNA was targeted in cultured SW480 cells, a cell line of human colon adenocarcinoma, by transfecting a 21-nucleotide duplex siRNA derived from the HO-1 nucleotide sequence according to the method reported recently (Elbashir et al, 2001). Small interfering RNA-treated SW 480 cells underwent a significant apoptotic change, which was almost comparable to the effect of ZnPP IX added to the cell culture (data not shown). These data indicate a clear cause and effect relation for the HO-1-mediated antiapoptotic effect.

It is of considerable importance that bilirubin, which is converted from biliverdin, a product of $\mathrm{HO}$, significantly decreased the number of TUNEL-positive AH136B cells treated with ZnPP IX. Bilirubin appears to be one of the most abundant endogenous antioxidants in mammalian tissues and accounts for most of the antioxidant activity in human serum (Minetti et al, 1998). Bilirubin displayed potent scavenging activity against various oxidants including superoxide, peroxyl radical, and peroxynitrite (Minetti et al, 1998; Dore et al, 1999). More importantly, a neuroprotective effect of bilirubin derived from HO-2 has been shown for hydrogen peroxide-induced cytotoxicity in cultured rat primary neuronal cells (Dore et al, 1999). Since oxidative stress is suggested to be a potential mediator of apoptosis induction (Buttke and Sandstrom, 1994), it is reasonable that the antioxidant activity of bilirubin just mentioned may antagonise the apoptosis elicited by $\mathrm{HO}$ inhibitor treatment in AH136B tumours.

However, bilirubin is also reputed to be a potentially toxic agent, particularly when it accumulates in the serum of neonates and causes jaundice. At high concentrations, bilirubin is deposited in selected brain regions and produces neurotoxicity associated with kernicterus (Gourley, 1997). In our present study, no clearly dosedependent inhibitory effect of bilirubin on ZnPP IX-induced apoptosis of AH136B cells was observed with bilirubin concentrations at more than $0.1 \mu \mathrm{m}$. This incomplete inhibition of apoptosis by bilirubin may be attributed to the cytotoxic effect of bilirubin itself rather than its antioxidant activity.

Another explanation for the saturated antiapoptotic effect of bilirubin is that $\mathrm{CO}$, which is a catalytic by-product of HO-1 activity, may be involved in the cytoprotective mechanism of HO1. In fact, Choi's group demonstrated that TNF- $\alpha$-induced apoptosis in cultured fibroblasts was inhibited by $\mathrm{CO}$ exposure (Petrache et al, 2000). Moreover, a low concentration of CO can provide protection against hyperoxic lung injury in vivo (Otterbein et al, 1999).

$\mathrm{CO}$ has been suggested to function as a neurotransmitter and also as an endogenous modulator of vascular perfusion in the liver through a mechanism analogous to that of NO (Suematsu et al, 1994). Zinc protoporphyrin IX was previously shown to reduce the tumour blood flow relatively selectively via mechanisms unrelated to HO inhibition (Tozer et al, 1998). It is important to confirm the lack of NOS inhibition by ZnPP IX, because NO has a biological effect very similar to HO-1 in terms of sustaining the solid tumour growth (Doi et al, 1996) as well as antioxidant effect. However, ZnPP IX affected neither tumour blood flow nor NO biosynthesis in the AH136B solid tumour tissue; whereas, tumour blood flow was significantly decreased by treatment with an NOS inhibitor (LNAME). These data suggest that NO rather than $\mathrm{CO}$ derived from $\mathrm{HO}$ may be the dominant modulator of tumour blood flow, at least in this solid tumour model.

Although several reports have shown a cytoprotective effect of HO-1 (Dennery et al, 1997; Suttner et al, 1999), contradictory effects of the biological consequences of overexpression of HO-1 have also been reported. Specifically, a study by Suttner and Dennery (1999) indicated that overexpression of HO-1 could exacerbate the oxidative stress of cells, and they revealed a critical role of reactive iron (ferric iron, $\mathrm{Fe}^{2+}$ ) released during $\mathrm{HO}$-catalytic decomposition of the porphyrin ring of haem in determining the consequence of $\mathrm{HO}$ expression.

In our own study, we assumed that some other cytoprotective system may occur to compensate for such a disadvantage of HO-1 induction in our experimental solid tumour. HSP70, which is one of the most important HSPs ubiquitously distributed in mammalian systems (Schlesinger, 1990; Xu et al, 1997), was expressed by AH136B cells and solid tumours. However, although HSP70 has been reported to be induced by NO exposure (Xu et al, 1997), our present analysis of HSP70 with NO donors and NOS inhibitors in vitro and in vivo showed that NO does not participate in HSP70 upregulation in AH136B cells. Thus, we suggest that HSP70 expression in AH136B tumours may be positively regulated by ischaemia or hypoxia through a mechanism different from HO-1 induction involving $\mathrm{NO}$.

AH136B experimental solid tumour tissues produce a high amount of NO, which seems to sustain rapid tumour growth, as we reported previously (Doi et al, 1996). NO mediates angiogenesis and enhanced vascular permeability in solid tumour (Jenkins et al, 1995; Wu et al, 1998), and is implicated in the maintenance of 
blood flow in the neovasculature of the tumour (Tozer et al, 1998). In addition, it has been reported that NO inhibits apoptosis and its mechanism appears to be via inhibition of the caspase protease cascade (Mannick et al, 1994; Ogura et al, 1998). However, no significant modification of NO production was observed with ZnPP IX treatment, as determined by microdialysis-based $\mathrm{NO}_{2}^{-}$ and $\mathrm{NO}_{3}^{-}$measurement in our experimental model, indicating that the apoptotic change in the AH136B solid tumours after ZnPP IX treatment depended mostly on the specific suppression of $\mathrm{HO}$ activity.

In conclusion, our current study indicates that HO-1 may function as an antiapoptotic defense system for the tumour, and it may also have important protective and beneficial effects for tumour cells against oxidative stress occurring during rapid growth of solid tumour in vivo. Thus, HO-1 may become a potential target for cancer chemotherapeutic agents, particularly in

\section{REFERENCES}

Akaike T, Inoue K, Okamoto T, Nishino H, Otagiri M, Fujii S, Maeda $\mathrm{H}$ (1997) Nanomolar quantification and identification of various nitrosothiols by high performance liquid chromatography coupled with flow reactors of metals and Griess reagent. J Biochem 122: 459-466

Bastian NR, Yim CY, Hibbs Jr JB, Samlowski WE (1994) Induction of ironderived EPR signals in murine cancers by nitric oxide. Evidence for multiple intracellular targets. J Biol Chem 269: 5127-5131

Bouton C, Demple B (2000) Nitric oxide-inducible expression of haem oxygenase-1 in human cells. J Biol Chem 275: 32688-32693

Buttke TM, Sandstrom PA (1994) Oxidative stress as a mediator of apoptosis. Immunol Today 15: 7-10

Dennery PA, Sridhar KJ, Lee CS, Wong HE, Shokoohi V, Rodgers PA, Spitz DR (1997) Haem oxygenase-mediated resistance to oxygen toxicity in hamster fibroblasts. J Biol Chem 272: 14937 - 14942

Doi K, Akaike T, Fujii S, Tanaka S, Ikebe N, Beppu T, Shibahara S, Ogawa $M$, Maeda $H$ (1999) Induction of haem oxygenase-1 nitric oxide and ischaemia in experimental solid tumours and implications for tumour growth. Br J Cancer 80: 1945-1954

Doi K, Akaike T, Horie H, Noguchi Y, Fujii S, Beppu T, Ogawa M, Maeda H (1996) Excessive production of nitric oxide in rat solid tumour and its implication in rapid tumour growth. Cancer 77: 1598-1604

Dore S, Takahashi M, Ferris CD, Zakhary R, Hester LD, Guastella D, Snyder SH (1999) Bilirubin, formed by activation of haem oxygenase-2, protects neurons against oxidative stress injury. Proc Natl Acad Sci USA 96: $2445-2450$

Drummond GS, Kappas A (1981) Prevention of neonatal hyperbilirubinemia by tin protoporphyrin IX, a potent competitive inhibitor of haem oxidation. Proc Natl Acad Sci USA 78: 6466-6470

Elbashir SM, Harborth J, Lendeckel W, Yalcin A, Weber K, Tuschl T (2001) Duplexes of 21-nucleotide RNAs mediate RNA interference in cultured mammalian cells. Nature 411: 494-498

Enari M, Talanian RV, Wong WW, Nagata S (1996) Sequential activation of ICE-like and CPP32-like proteases during Fas-mediated apoptosis. Nature 380: $723-726$

Foresti R, Motterlini R (1999) The haem oxygenase pathway and its interaction with nitric oxide in the control of cellular homeostasis. Free Radicals Res 31: $459-475$

Gourley GR (1997) Bilirubin metabolism and kernicterus. Adv Pediatr 44: $173-229$

Hancock WW, Buelow R, Sayegh MH, Turka LA (1998) Antibody-induced transplant arteriosclerosis is prevented by graft expression of antioxidant and anti-apoptotic genes. Nat Med 4: $1392-1396$

Ikebe N, Akaike T, Miyamoto Y, Hayashida K, Yoshitake J, Ogawa M, Maeda H (2000) Protective effect of $S$-nitrosylated $\alpha_{1}$-protease inhibitor on hepatic ischemia-reperfusion injury. J Pharmacol Exp Ther 295: 904-911

Jenkins DC, Charles IG, Thomsen LL, Moss DW, Holmes LS, Baylis SA, Rhodes P, Wetmore K, Emson PC, Moncada S (1995) Role of nitric oxide in tumour growth. Proc Natl Acad Sci USA 92: $4392-4396$

Keyse SM, Tyrrell RM (1989) Haem oxygenase is the major 32-kDa stress protein induced in human skin fibroblasts by UVA radiation, hydrogen peroxide, and sodium arsenite. Proc Natl Acad Sci USA 86: 99-103 combinations with conventional agents. The present study warrants further investigation to develop new tactics for antitumour treatment with the use of HO inhibitors such as ZnPP IX or its polymer-conjugated derivatives with improved pharmacological properties (Sahoo et al, 2002).

\section{ACKNOWLEDGEMENTS}

We thank Ms Judith B Gandy for excellent editorial work on our manuscript. This work was supported in part by grants-in-aid for scientific research from the Ministry of Education, Culture, Sports, Science and Technology, and the Ministry of Health, Labour and Welfare of Japan.

Kim YM, Bergonia H, Lancaster Jr JR (1995) Nitrogen oxide-induced autoprotection in isolated rat hepatocytes. FEBS Lett 374: 228-232

Kimura M, Matsumura Y, Konno T, Miyauchi Y, Maeda H (1990) Enzymatic removal of bilirubin toxicity by bilirubin oxidase in vitro and excretion of degradation products in vivo. Proc Soc Exp Biol Med 195: $64-69$

Lutton JD, Abraham NG, Drummond GS, Levere RD, Kappas A (1997) Zinc porphyrins: potent inhibitors of hematopoiesis in animal and human bone marrow. Proc Natl Acad Sci USA 94: 1432-1436

Maines MD (1997) The haem oxygenase system: a regulator of second messenger gases. Annu Rev Pharmacol Toxicol 37: 517-554

Mannick JB, Asano K, Izumi K, Kieff E, Stamler JS (1994) Nitric oxide produced by human $\mathrm{B}$ lymphocytes inhibits apoptosis and Epstein - Barr virus reactivation. Cell 79: $1137-1146$

Minetti M, Mallozzi C, Di Stasi AM, Pietraforte D (1998) Bilirubin is an effective antioxidant of peroxynitrite-mediated protein oxidation in human blood plasma. Arch Biochem Biophys 352: 165-174

Mitani K, Fujita H, Fukuda Y, Kappas A, Sassa S (1993) The role of inorganic metals and metalloporphyrins in the induction of haem oxygenase and heat-shock protein 70 in human hepatoma cells. Biochem J 290: $819-825$

Motterlini R, Foresti R, Bassi R, Calabrese V, Clark JE, Green CJ (2000) Endothelial haem oxygenase-1 induction by hypoxia. Modulation by inducible nitric-oxide synthase and S-nitrosothiols. J Biol Chem 275: $13613-13620$

Ogura T, DeGeorge G, Tatemichi M, Esumi H (1998) Suppression of antimicrotubule agent-induced apoptosis by nitric oxide: possible mechanism of a new drug resistance. Jpn J Cancer Res 89: 199-205

Ohta K, Araki N, Shibata M, Hamada J, Komatsumoto S, Shimazu K, Fukuuchi Y (1994) A novel in vivo assay system for consecutive measurement of brain nitric oxide production combined with the microdialysis technique. Neurosci Lett 176: $165-168$

Otterbein LE, Mantell LL, Choi AM (1999) Carbon monoxide provides protection against hyperoxic lung injury. Am J Physiol 276: L688-L694

Petrache I, Otterbein LE, Alam J, Wiegand GW, Choi AM (2000) Haem oxygenase- 1 inhibits TNF- $\alpha$-induced apoptosis in cultured fibroblasts. Am J Physiol 278: L312 - L319

Sahoo SK, Sawa T, Fang J, Tanaka S, Miyamoto Y, Akaike T, Maeda H (2002) Pegylated zinc protoporphyrin: a water-soluble heme oxygenase inhibitor with tumour-targeting capacity. Bioconjug Chem 13: 1031-1038 Schlesinger MJ (1990) Heat shock proteins. J Biol Chem 265: $12111-12114$

Shibahara S, Muller RM, Taguchi H (1987) Transcriptional control of rat haem oxygenase by heat shock. J Biol Chem 262: 12889-12892

Soares MP, Lin Y, Anrather J, Csizmadia E, Takigami K, Sato K, Grey ST, Colvin RB, Choi AM, Poss KD, Bach FH (1998) Expression of haem oxygenase-1 can determine cardiac xenograft survival. Nat Med 4: 1073 1077

Suematsu M, Kashiwagi S, Sano T, Goda N, Shinoda Y, Ishimura Y (1994) Carbon monoxide as an endogenous modulator of hepatic vascular perfusion. Biochem Biophys Res Commun 205: 1333 - 1337

Suttner DM, Dennery PA (1999) Reversal of HO-1 related cytoprotection with increased expression is due to reactive iron. FASEB J 13: $1800-1809$ 
Suttner DM, Sridhar K, Lee CS, Tomura T, Hansen TN, Dennery PA (1999) Protective effects of transient HO-1 overexpression on susceptibility to oxygen toxicity in lung cells. Am J Physiol 276: L443 - L451

Tenhunen R, Marver HS, Schmid R (1968) The enzymatic conversion of haem to bilirubin by microsomal haem oxygenase. Proc Natl Acad Sci USA 61: $748-755$

Tenhunen R, Marver HS, Schmid R (1970) The enzymatic catabolism of hemoglobin: stimulation of microsomal haem oxygenase by hemin. J Lab Clin Med 75: $410-421$

Tozer GM, Prise VE, Motterlini R, Poole BA, Wilson J, Chaplin DJ (1998) The comparative effects of the NOS inhibitor, $N^{\omega}$-nitro-L-arginine, and the haemoxygenase inhibitor, zinc protoporphyrin IX, on tumour blood flow. Int J Radiat Oncol Biol Phys 42: 849-853

Workman P, Twentyman P, Balkwill F, Balmain A, Chaplin D, Double J, Embleton J, Newell D, Raymond R, Stables J, Stephens T, Wallace J (1998) United Kingdom Co-ordinating Committee on Cancer Research
(UKCCCR) guidelines for the welfare of animals in experimental neoplasia (Second Edition). Br J Cancer 77: $1-10$

Wu J, Akaike T, Maeda H (1998) Modulation of enhanced vascular permeability in tumours by a bradykinin antagonist, a cyclooxygenase inhibitor, and a nitric oxide scavenger. Cancer Res 58: $159-165$

Xu Q, Hu Y, Kleindienst R, Wick G (1997) Nitric oxide induces heat-shock protein 70 expression in vascular smooth muscle cells via activation of heat shock factor 1. J Clin Invest 100: 1089-1097

Yang G, Nguyen X, Ou J, Rekulapelli P, Stevenson DK, Dennery PA (2001) Unique effects of zinc protoporphyrin on $\mathrm{HO}-1$ induction and apoptosis. Blood 97: 1306 - 1313

Zakhary R, Gaine SP, Dinerman JL, Ruat M, Flavahan NA, Snyder SH (1996) Haem oxygenase 2: endothelial and neuronal localization and role in endothelium-dependent relaxation. Proc Natl Acad Sci USA 93: 795 798 